\title{
Por que as mulheres são minoria nos cursos de computação? Um estudo desta situação na cidade de Ouro Branco-MG
}

\author{
Simone S. Sidnei ${ }^{1}$, Márcio A. Miranda ${ }^{1}$, Suelen M. de Paula ${ }^{1}$ \\ ${ }^{1}$ Departamento de Computação \\ Instituto Federal de Minas Gerais (IFMG) \\ R. Afonso Sardinha, 90 - Ouro Branco, MG - Brasil \\ shirleysimone.ss@gmail.com, \{marcio.assis, suelen.mapa\}@ifmg.edu.br
}

\begin{abstract}
This work analyzes the low representativeness of the female public in undergraduate programs related to computer science. We interviewed upper year students from public and private high schools in Ouro Branco-MG. The research analyzed whether the financial condition of the students and the support and encouragement they receive from the family and the school are decisive in choosing a course. In the end, we highlighted some questions to guide further studies.
\end{abstract}

Resumo. O presente trabalho trata-se de um estudo acerca da baixa representatividade do público feminino na área da computação. Foram entrevistados alunos (meninos e meninas) do terceiro ano do Ensino Médio das escolas públicas e privadas em Ouro Branco-MG. A pesquisa analisou se a condição financeira das alunas e o apoio e incentivo que elas recebem da família e da escola são determinantes na escolha por um curso na área de computação. Ao final, foram apontadas questões para um maior aprofundamento.

\section{Introdução}

Computação é uma área com crescente demanda de profissionais. Entretanto, ao pensar em computadores vem logo a lembrança de nomes como Mark Zuckerberg, Bill Gates, Steve Jobs, tendo predominantemente homens como seus principais representantes. Mas essa realidade nem sempre foi assim. Muitos feitos na computação tiveram mulheres como principais agentes. Por exemplo, a primeira pessoa a criar um algoritmo capaz de ser computável por uma máquina programável foi a britânica Ada Lovelace. Ou, como relatam [Schwartz et al. 2006], o desenvolvimento da linguagem COBOL foi liderado por uma mulher chamada Grace Murray Hopper.

Esses fatos mostram que antes da propagação dos computadores pessoais e da internet, as mulheres tiveram significativas contribuições em carreiras relacionadas à Engenharia e Ciências Exatas e da Terra. Contudo, o que se observa no Brasil e no mundo é uma baixa presença feminina em carreiras relacionadas a essas áreas do conhecimento [Sales et al. 2014] e [Maia 2016].

De acordo com o censo da educação superior realizado em 2015 as mulheres representam $60 \%$ das pessoas que concluíram cursos superiores no Brasil. Porém, quando são considerados apenas os cursos relacionados às ciências (Engenharias, Matemática, Medicina, Física, Química, Ciência da Computação, dentre outros), a participação feminina cai para $41 \%$, índice que não registra aumento desde 2000. 
Diante desse contexto de disparidade, as perguntas que fazemos são: como uma área de atuação em crescente destaque, financeiramente atrativa e com expectativas positivas ainda possuem uma participação pequena das mulheres? Ou, por que as mulheres, após ter contribuído tanto para o seu desenvolvimento, hoje são a minoria nesse campo? O que possivelmente influencia o público feminino na escolha de sua profissão ou por fazer carreira na área de tecnologia? Essas perguntas trazem questionamentos que devem provocar mudanças de atitude por parte de toda a sociedade.

Sendo assim, esse trabalho tem como objetivo principal investigar o comportamento dos alunos (meninas e meninas) das escolas públicas e privadas da cidade de Ouro Branco, Minas Gerais, com o intuito de identificar que fatores podem influenciar na escolha das alunas por um curso na área de computação. Seria a condição econômica das alunas e o apoio e incentivo que elas recebem da família e da escola aspectos determinantes para a escolha de seus cursos superiores? Espera-se que essa pesquisa possa retratar o cenário atual dessa questão.

\section{Revisão da Literatura}

A revisão da leitura realizada teve como intuito principal levantar pressupostos que pudessem nortear a pesquisa a ser realizada. Foram selecionados 11 artigos: [Stoilescu and McDougall 2011], [Olinto 2011], [de Sousa et al. 2017], [Moreira et al. 2014], [Gomes et al. 2014], [Nunes et al. 2015], [Mattos et al. 2016], [Holanda et al. 2016], [Maia 2016], [Rosa and Quirino 2016], [de Holanda et al. 2017]. A partir deles, efetuou-se uma leitura crítica, da qual foram extraídas informações que ampliaram nossa visão a cerca do problema abordado.

Foi possível levantar duas questões para nortear esta pesquisa: (i) A ausência de incentivo por parte da família e da escola influencia na escolha por um curso na área da computação? (ii) Seria a condição econômica um item decisivo na escolha dessa área de atuação?

A fim de validar tais pressupostos, uma pesquisa qualitativa foi conduzida entre os alunos (meninos e meninas) do terceiro ano do Ensino Médio da cidade de Ouro Branco. Maiores detalhes podem ser observados na seção seguinte.

\section{Metodologia}

A pesquisa foi executada ao longo do ano de 2018 e foi realizada em duas escolas particulares e duas escolas públicas, com vistas a analisar as respostas de alunos de classes sociais diferentes e comparar fatores que interferem em suas escolhas profissionais.

Foram entrevistados 138 estudantes do último ano do Ensino Médio: 41 nas escolas particulares (22 alunas e 19 alunos) e 97 nas escolas públicas (66 alunas e 31 alunos). Ademais, O questionário empregado é composto por 14 questões de múltipla escolha e pode ser consultado por meio do formulário <https://bit.ly/2Nzyysg $>$.

Uma pergunta que pode ser levantada aqui é: por que os meninos foram incluídos nessa pesquisa? O racional utilizado para estruturação do estudo partiu das questões de pesquisa extraídas da revisão de literatura. Se as supramencionadas questões forem pertinentes, as alunas das escolas públicas, em sua maioria, darão preferência por uma área de atuação que não seja computação. Enquanto os meninos das escolas particulares, 
em sua maioria, optarão por um curso na área da computação. Os resultados apurados são apresentados na próxima seção.

\section{Resultados}

Na Figura 1 são apresentados os resultados que têm relação direta com o que se deseja comprovar.

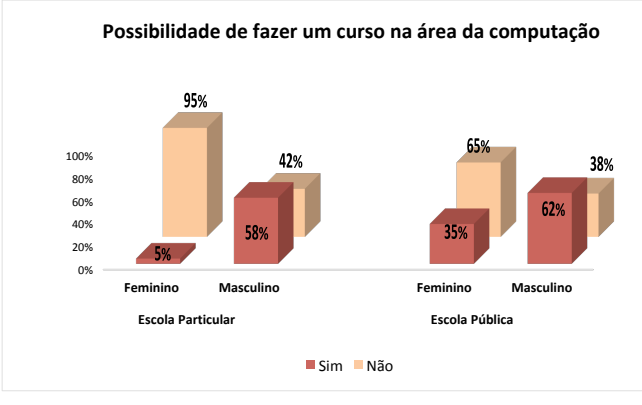

(a) Possibilidade de fazer um curso na área.

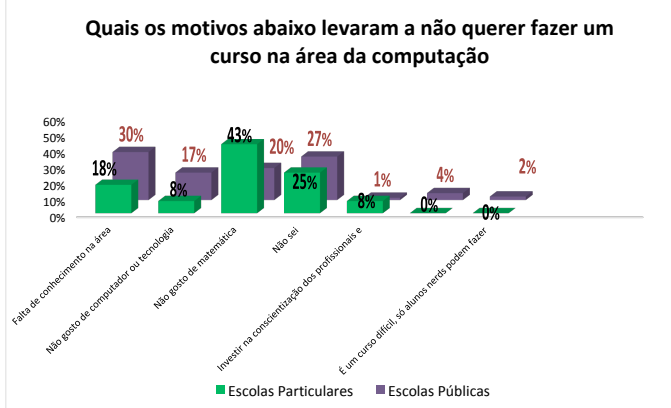

(c) Motivos da não escolha por um curso da área.

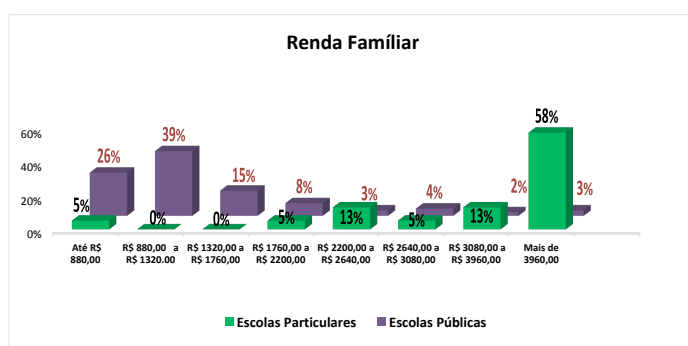

(b) Distribuição da renda familiar.

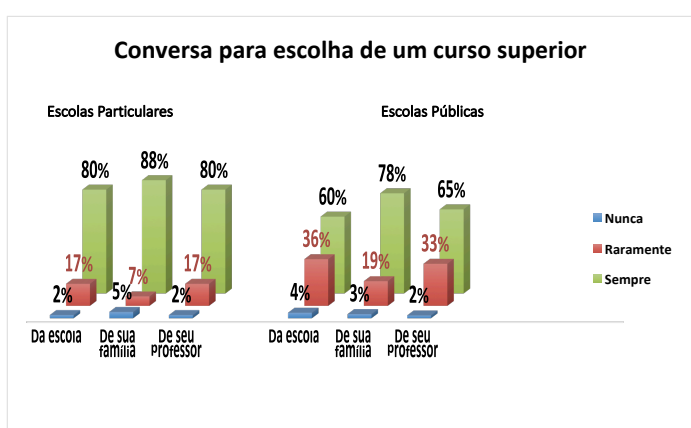

(d) Interação entre alunos, escola e família.

Figura 1. Principais gráficos gerados com a pesquisa realizada.

O Gráfico (a) apresenta as respostas dos alunos quanto à possibilidade de fazerem um curso na área da computação. No estudo, era esperado que principalmente os meninos das escolas privadas tivessem alta preferência pelo curso. O que apuramos, na verdade, foi uma preferência média de 58\% (um padrão semelhante foi observado nas respostas dos alunos das escolas públicas). Além disso, também era esperado que as meninas das escolas públicas tivessem uma baixa preferência por computa ção e, de acordo com o verificado, $35 \%$ dessas alunas fariam um curso na área.

Para uma análise mais acurada desta constatação, avaliamos as respostas dos alunos quando questionados sobre a renda de sua família. O resultado obtido pode ser observado no Gráfico (b). Pode-se afirmar que a renda das famílias das escolas públicas varia entre baixa e regular. Por outro lado, a maioria das famílias das escolas particulares possui renda considerada alta para o perfil da região em estudo.

Os alunos ainda foram indagados sobre a falta de interesse pela área de computação. Como mostra o Gráfico (c), a maioria dos alunos das escolas particulares demonstraram fazer uma associação negativa entre matemática e computação. Já nas escolas públicas, a falta de interesse se deu por falta de conhecimento da área. 
A fim de apurar se os estudantes recebem suporte nas suas decisões, eles foram questionados sobre o incentivo que recebem para a escolha de um curso de graduação por parte das famílias, da escola e/ou dos professores. Observa-se, a partir dos resultados apresentados no Gráfico (d), que tanto os meninos quanto as meninas das escolas particulares e públicas conversam e interagem com familiares e equipe escolar ao escolher um curso superior.

\section{Discussão dos Resultados}

De modo geral, os resultados apresentados na seção anterior apontaram que a cidade Ouro Branco segue uma tendência mundial, ou seja, o público feminino tende a preterir cursos da área de computação.

Era esperado que quanto maior fosse a condição econômica do aluno, maiores seriam as chances de ele optar por um curso da área de computação, mas isso não se confirmou. Foi observado, entretanto, que os alunos e alunas das escolas públicas, mesmo pertencendo a uma família com renda menor, fariam um curso na área da computação. Tal fato leva a crer que a falta de conhecimento gera impressões erradas e negativas sobre a área, que é associando a disciplinas como a matemática apenas. Assim sendo, os alunos acabam optando por cursos da área de humanas.

O estudo também averiguou que as conversas e interação dos alunos com suas famílias e escola pouco influenciam na escolha das alunas por cursos da área de computação. $\mathrm{O}$ que percebemos foi que os estudantes conversam com professores e seus pais sobre a futura profissão, porém, não foi é possível saber como essa conversa/apoio ocorre.

Desse modo, não podemos afirmar quais são, de fato, os incentivos que os alunos recebem em casa ou se a recusa pela computação está ligada a uma questão cultural/regional. Não sabemos também se a não preferência das meninas por este campo profissional pode ser explicada pelo fato de elas não terem contato com a tecnologia na infância ou se falta uma personalidade em quem elas se espelharem. Para descobrir as respostas para tais indagações, precisaríamos de uma nova pesquisa a fim de examinar cada ponto levantado.

\section{Conclusão}

Neste trabalho foi realizada uma pesquisa a fim de investigar fatores que podem influenciar a escolha profissional dos alunos e alunas do município de Ouro Branco por cursos de graduação em áreas tecnológicas, especialmente na área de computação. Neste contexto, destaca a revisão de literatura, que foi fundamental definir as questões que direcionaram a pesquisa realizada.

De modo geral, as alunas que fizeram parte da pesquisa não têm a intenção de fazer curso de graduação na área da computação. Se o objetivo é aumentar a participação feminina nos cursos da área de computação, então pouco adianta ter apoio da família ou da escola, caso esse apoio não seja direcionado. Elas precisam ter exemplos a seguir, conhecer as possibilidades de atuação e entender que podem mudar sua realidade social a partir da tecnologia.

Por fim, listamos aqui algumas sugestões de trabalhos futuros que podem dar continuidade a esta pesquisa: (i) Investigar a qualidade dos incentivos que as meninas re- 
cebem e como eles influenciam nas escolhas da futura profissão; (ii) Promover projetos de extensão para divulgar a área e também oportunidades profissionais que despertem o interesse da comunidade local, especialmente das meninas.

\section{Referências}

de Holanda, M. T., Mourão, R., Ramos, G. N., de Araújo, A. P. F., and Walter, M. E. T. (2017). Uma pesquisa com alunas do ensino fundamental e médio sobre os cursos da área de computação. In Anais do XI WIT. SBC.

de Sousa, J. S., de Souza, M. C., Lopes, M. D., and da Rocha Fernandes, A. M. (2017). Mulheres digitais: Uma análise da participação das mulheres nos cursos de ciência da computação e engenharia de computação no brasil e na universidade univali. Anais do Computer on the Beach, pages 404-413.

Gomes, W. F., Louzada, C. S., Nunes, M. A. S. N., Salgueiro, E. M., and Andrade, B. T. (2014). Incentivando meninas do ensino médio à área de ciência da computação usando o scratch como ferramenta. In Anais do Workshop de IE, volume 20, page 223.

Holanda, M., Walter, M. E. M. T., and Araújo, A. P. F. d. (2016). Meninas. comp: Computação também é coisa de menina.

Maia, M. M. (2016). Limites de gênero e presença feminina nos cursos superiores brasileiros do campo da computação. cadernos pagu, (46):223-244.

Mattos, F., Ferreira, V., and Anacleto, J. (2016). O ensino de programaçao com scratch e seu impacto na opçao profissional para meninas. In Brazilian Symposium on Computers in Education (Simpósio Brasileiro de Informática na Educação-SBIE), volume 27, page 300 .

Moreira, J. A., Mattos, G. d. O., and Reis, L. (2014). Um panorama da presença feminina na ciência da computação. Anais do XVIII Encontro Internacional da Rede Feminista Norte e Nordeste de Estudos e Pesquisa sobre a Mulher e Relações de Gênero.

Nunes, M., Rodrigues, L. F., Martinhago, A. Z., Soares, L. S., and Reis, R. C. D. (2015). Meninas++: uma iniciativa para fomentar a participação feminina na área de computação. Tecnologias, Sociedade e Conhecimento Campinas, 3(1).

Olinto, G. (2011). A inclusão das mulheres nas carreiras de ciência e tecnologia no brasil. Inclusão Social, 5(1).

Rosa, M. A. G. and Quirino, R. G. (2016). Relações de gênero na ciência e tecnologia $(\mathrm{c} \& \mathrm{t})$ : estudo de caso de um centro federal de educação tecnológica. Diversidade e Educação, 4(8):42-55.

Sales, A., Calado, B., Silva, D. R., Mattos, G. d. O., and Moreira, J. A. (2014). Dificuldades para o ingresso e permanência na ciência e engenharia da computação: um olhar feminino. 18th Redor-UFRPE.

Schwartz, J., Casagrande, L. S., Leszczynski, S. A. C., and Carvalho, M. G. d. (2006). Mulheres na informática: quais foram as pioneiras? cadernos pagu, (27):255-278.

Stoilescu, D. and McDougall, D. (2011). Gender digital divide and challenges in undergraduate computer science programs. Canadian Journal of Education, 34(1):308-333. 